\title{
Pengembangan Teknologi Probio_FM untuk Pengolahan Pupuk Organik pada Kelompok Peternak Sapi di Desa Lubuk Lingkuk, Kabupaten Bangka Tengah
}

\section{(Probio_FM Technology Development for Organic Fertilizer Processing Cattle Farmer Groups in Lubuk Lingkuk Village, Central Bangka District)}

\author{
Rufti Puji Astuti ${ }^{*}$, Evahelda1, Nur Annis Hidayati² \\ 1 Program Studi Agribisnis, Fakultas Pertanian Perikanan dan Biologi, Universitas Bangka Belitung, \\ Balunijuk, Kecamatan Merawang, Kabupaten Bangka, Provinsi Kepulauan Bangka Belitung 33172 \\ 2 Program Studi Biologi, Fakultas Pertanian Perikanan dan Biologi, Universitas Bangka Belitung, \\ Balunijuk, Kecamatan Merawang, Kabupaten Bangka, Provinsi Kepulauan Bangka Belitung 33172 \\ *Penulis Korespondensi: ruftipuji24@gmail.com \\ Diterima September 2019/Disetujui Februari 2020
}

\begin{abstract}
ABSTRAK
Salah satu manfaat penerapan sistem integrasi sapi dan kelapa sawit adalah tersedianya sumber pakan bagi ternak dari perkebunan sawit, sebaliknya feses sapi berpotensi digunakan sebagai pupuk untuk tanaman sawit. Tujuan kegiatan pengabdian ini adalah untuk memberdayakan peternak dalam mengolah pupuk kompos limbah feses sapi dengan teknologi probio_Fm. Metode pelaksanaan dilakukan melalui tiga tahapan yaitu, sosialisasi, demontrasi, serta monitoring dan evaluasi. Analisis data dilakukan dengan analisis deskriptif kualitatif. Hasil kegiatan pengabdian menunjukkan bahwa pelatihan yang diberikan telah mampu memberdayakan peternak untuk mengolah pupuk kompos limbah feses sapi dengan teknologi probio_Fm. Proses pembuatan pupuk kompos dengan teknologi probio_Fm dinilai peternak mudah dipahami dengan perolehanan nilai ketercapaian materi mencapai $85 \%$. Pembuatan pupuk kompos dengan teknologi probio_Fm juga diminati peternak, sebanyak $50 \%$ peternak menyatakan berminat sampai sangat berminat mengolah limbah feses menjadi pupuk kompos dengan teknologi probio_Fm. Hasil kegiatan pengabdian juga menunjukkan bahwa peternak saat ini sudah trampil membuat pupuk kompos dengan menerapkan teknologi probio_Fm. Peternak pada kelompok Saling Gumilang sudah berhasil memproduksi 1 ton pupuk kompos. Pupuk kompos hasil produksi kelompok saling gumilang secara umum memiliki ciri fisik warna cokelat kehitaman, bau tidak menyengat, dan memiliki tekstur gembur. Optimalisasi penggolahan pupuk kompos di Desa Lubuk Lingkuk dapat dilakukan dengan penerapan teknologi probio_Fm secara berkelanjutan, agar manfaat penerapan sistem integrasi sapi dan kelapa sawit semakin banyak dirasakan peternak.
\end{abstract}

Kata kunci: feses sapi, kompos, teknologi probio_Fm

\begin{abstract}
The integrated farming system between cattle and oil palm plantation provide both food source for cattle and fertilizer for the plant. This community partnership program aimed to give technical assistance to cattle farmers in producing organic fertilizer with probio_Fm technology. The activity was consisted of three steps, which were introduction, demonstration (laboratory and field demonstration), and control (monitoring and evaluation). The success of the program was qualitatively analysed. As a result, the Saling Gumilang cattle farmer group have been able to apply probio_Fm technology in cattle faeces composting. The farmers absorb $85 \%$ of the information given, which meant that the information was considered easy to be understood. As much as $50 \%$ of the farmers stated their preference in sustainable use of the probio_Fm technology. The farmers had shown their skills to produce organic fertilizer with probio_Fm technology without further asssitance. They produced one ton of organic fetilizer from cattle faeces with probio_Fm technology. The fertilizer had browny-blackish colour, weak undesirable odor, and loose texture. In the future, sustainable implementation of the probio_Fm technology is expected to optimize the cattle faeces composting in order to get a higher advantages of the integrated farming system between cattle and oil palm plantation.
\end{abstract}

Keywords: cattle faeces, compost, probio_Fm technology 


\section{PENDAHULUAN}

Pemerintah Kabupaten Bangka Tengah optimis mengandalkan sub-sektor perkebunan dan peternakan guna mewujudkan visi menuju masyarakat sejahtera berbasis ekonomi kerakyatan dan berkelanjutan. Pemerintah dalam hal ini menetapkan bahwa penguasaan dan pengembangan iptek merupakan kunci keberhasilan dalam memperkuat pondasi ekonomi kerakyatan yang merata dan berkelanjutan. Pemerintah menargetkan terdapat 30 kelompok yang memiliki kemampuan dalam pengembangan dan penguasaan teknologi pada tahun 2019 (RPJMD Bangka Tengah 2016-2021).

Sistem integrasi sapi dan kelapa sawit atau lebih dikenal Siska, merupakan program unggulan Pemerintah Bangka Tengah guna meningkatkan produksi hasil perkebunan dan sekaligus produk peternakan. Konsep utama penerapan sistem integrasi sapi kelapa sawit adalah mengelola usaha tani sapi dengan memanfaatkan limbah perkebunan sawit sebagai sumber bahan pakan, sebaliknya kotoran dari ternak sapi dijadikan pupuk untuk tanaman sawit (Tiesnamurti et al. 2014). Desa Lubuk Lingkuk berpotensi untuk menjadi desa percontohan dalam penerapan sistem integrasi sapi kelapa sawit ini. Keberadaan kebun sawit milik masyarakat maupun perusahaan swasta berpotensi untuk menyediakan sumber pakan bagi ternak, dan sebaliknya feses sapi berpotensi untuk pupuk tanaman sawit. Faktanya penggunaan feses sapi sebagai pupuk tanaman sawit oleh sebagian peternak masih dilakukan tanpa pengolahan, sedangkan secara keseluruhan lebih banyak petani masih menggunakan pupuk kimia. Kelompok Saling Gumilang di Desa Lubuk Lingkuk masih terkendala masalah penguasaan teknologi pengolahan pupuk, kelompok tidak berpengalaman, dan belum memiliki pengetahuan yang cukup tentang adanya teknologi pengolahan pupuk dari feses sapi.

Pengolahan pupuk organik berbahan dasar limbah feses sapi penting dilakukan. Penggunaan pupuk organik berkelanjutan oleh petani dapat mengurangi penggunaan pupuk kimia yang dinilai dapat merusak kesuburan tanah. Sifat bahan kimia adalah sulit untuk terurai kembali, sehingga penggunaan berkelanjutan, salah satunya berdampak pada pengerasan tanah (Rohani et al. 2016). Penggunaan pupuk organik berbahan dasar limbah kotoran oleh petani juga perlu dioptimalkan. Menurut (Syarief et al. 2016) penggunaan pupuk organik feses sapi yang telah diolah dengan proses pengomposan lebih cepat dapat dimanfaatkan bila dibandingkan tanpa diolah. Solusi yang ditawarkan untuk penyelesaian masalah di kelompok saling gumilang adalah dengan penerapan teknologi probio_Fm dalam pengolahan pupuk organik.

Teknologi probio_Fm merupakan teknologi tepat guna dan dapat diandalkan untuk optimalisasi pengolahan feses sapi menjadi pupuk organik. Probio_Fm merupakan probiotik cair mengandung beberapa spesies bakteri asam laktat, yang merupakan hasil isolasi mikrob, diambil dari saluran pencernaan itik Kerinci (Manin et al. 2003; Manin et al. 2010 ). Peran probio_Fm dalam pengolahan pupuk organik feses sapi adalah sebagai bahan pengurai, yaitu berupa cairan yang dapat mempercepat penguraian bahan organik, menghilangkan bau, dan menekan bakteri patogen (Syarief et al. 2016). Pengolahan pupuk kompos dengan teknologi probio_Fm dapat menghasilkan pupuk orrganik hasil fermentasi (porasi) berkualitas (Manin 2014; Adriani et al. 2016; Adriani \& Novra 2017)

Penggunaan teknologi probio_Fm dalam pengolahan pupuk organik telah digunakan kelompok tunas baru untuk penanganan limbah cair melalui pengolahan biourin, selain menjadikan proses penanganan limbah ramah lingkungan, pengaplikasian biourin pada tanaman tomat dapat mempercepat proses vegetatif (Astuti \& Pranoto 2018). Artinya pemanfaatan feses sapi sebagai pupuk kompos untuk tanaman selain mampu memengaruhi produktivitas tanaman juga berdampak pada perbaikan daya dukung lingkungan serta mengurangi pencemaran bau kandang (Okoroafor et al. 2013)

Penyebarluasan teknologi probio_Fm dan peranannya dalam pengolahan limbah feses sapi menjadi pupuk organik, dilakukan melalui pelaksanaan kegiatan dari Program Kemitraan Masyarakat (PKM). PKM kelompok peternak sapi guna pengembangan teknologi probio_Fm dalam pengolahan pupuk organik bertujuan mengembangkan sekelompok masyarakat yang tergabung dalam kelompok tani Saling Gumilang dengan menyelesaikan masalah pada bidang produksi melalui penerapan teknologi probioFm.

Tujuan kegiatan PKM ini adalah memberdayakan peternak dalam pengusaan teknologi pengolahan pupuk organik dengan teknologi probio_Fm. kemampuan dan penguasaan teknologi dalam pengolahan feses sapi menjadi 
pupuk organik diharapkan mampu mengubah minat dan perilaku peternak untuk menggolah dan menggunakan pupuk organik. Kegiatan ini penting dilakukan dalam rangka penyebarluasan teknologi, dan untuk memaksimalkan manfaat Siska. Wujud penyelesaian masalah akan dilakukan melalui pelatihan pengolahan pupuk berbahan dasar feses sapi menggunakan teknologi probio_Fm.

\section{METODE PELAKSANAAN KEGIATAN}

\section{Waktu dan Tempat}

Pengabdian dilaksanakan selama 4 bulan, sejak bulan Mei-Agustus 2019 pada kelompok tani Saling Gumilang, Desa Lubuk Lingkuk, Kecamatan Lubuk Besar, Kabupaten Bangka Tengah, Bangka Belitung. Pemilihan kelompok tani dilakukan atas pertimbangan bahwa peternak dari kelompok Saling Gumilang terampil memproduksi probio_Fm (F3/siap pakai).

\section{Alat dan Bahan}

Alat yang digunakan dalam pelaksanaan program pengolahan pupuk kompos dengan teknologi Probio_FM adalah terpal, skop, cangkul, ember, dan timbangan. Bahan yang digunakan feses sapi, serasah rumput kering, dedak padi, gula pasir, air dan Probio_FM

\section{Prosedur Kerja Pembuatan Pupuk Kompos dengan Teknologi Probio_FM}

Prosedur kerja pembuatan pupuk kompos dengan teknologi Probio_FM dilakukan melalui 8 tahapan, yaitu 1) Mempersiapkan alat dan bahan; 2) Pemisahan dan pemilihan feses dengan kadar air 30\%; 3) Penimbangan dan pencampuran feses dan serasah rumput kering sebanyak 1 ton dan dedak padi sebanyak $30 \mathrm{~kg}$; 4) Pembuatan larutan air gula pasir $1 \mathrm{~kg}$ dan ditambah probio_Fm 1 L; 5) Pengadukan bahan sampai

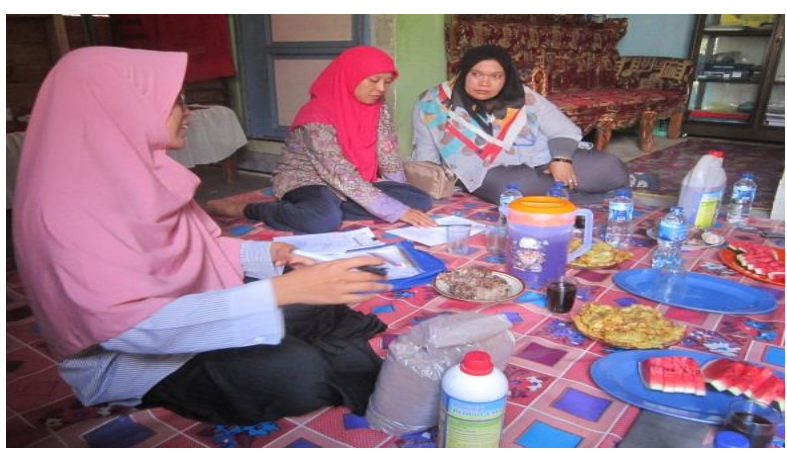

a homogen dan ketebalan tumpukan bahan $30 \mathrm{~cm}$; 6) Proses fermentasi dengan menutup bahan dengan plastik terpal; 7) Pembalikan kompos setelah 1 minggu masa fermentasi 8) Pemanenan pupuk kompos dengan membuka penutup plastik terpal dan aplikasi produk kompos.

\section{Bentuk Kegiatan}

Bentuk kegiatan yang dilakukan sosialisasi program dan materi, demonstrasi pembuatan pupuk kompos dengan teknologi probio_Fm, serta monitoring dan evaluasi program.

\section{Metode Pengumpulan dan Analisis Data}

Metode pengumpulan data dalam pelaksanaan program adalah dengan wawancara, penyebaran angket (lembar observasi) berisi tentang pemahaman materi, testimoni penggunaan teknologi probio_Fm, penilaian tentang sifat teknologi, dan minat penggunan teknologi. Analisis data menggunakan metode deskriptif kualitatif.

\section{HASIL DAN PEMBAHASAN}

Pelaksanaan program pengabdian masyarakat dilakukan secara sistematis dengan melibatkan kelompok Saling Gumilang. Pelaksanaan program dilakukan melalui 3 tahapan, yaitu sosialisasi kegiatan dan materi, demonstrasi pelatihan pengolahan pupuk organik, serta monitoring, dan evaluasi kegiatan.

\section{Sosialisasi}

Pelaksanaan kegiatan pengabdian dilawali dengan kegiatan sosialisasi. Bentuk sosialisasi yang dilakukan tidak hanya bertujuan untuk menyampaian program kegiatan PKM, Juga menjelaskan materi pelatihan maupun FGD pembentukan jadwal pelaksanaan (Gambar 1). Tim pengabdi memberi pengarahan kepada

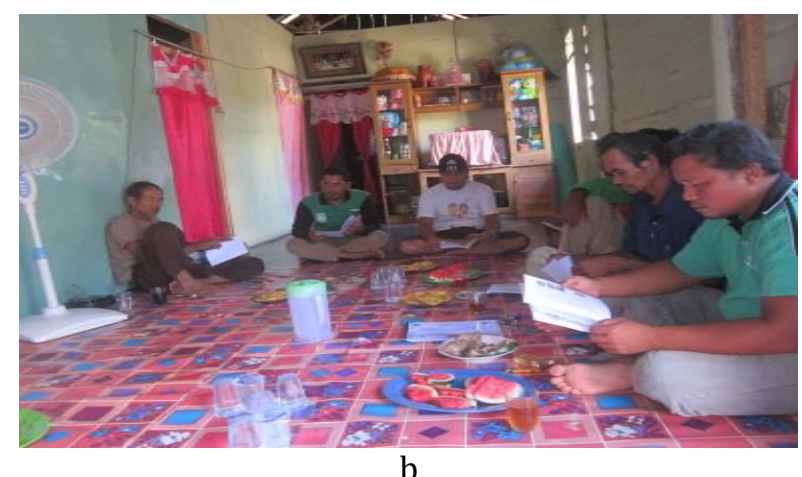

b

Gambar 1 Kegiatan sosialisasi program a) Penyampaian materi dan b) Penyampaian brosur. 
peserta bahwa salah satu program kegiatan pengabdian ini adalah pelatihan pengolahan pupuk organik berbahan dasar feses sapi dengan menggunakan teknologi probio_Fm. Tim pengabdi mengajak peserta secara aktif berpartisipasi menyepakati jadwal pelaksanaan program PKM. Hasil kegiatan FGD peternak dan tim pengabdi sepakat kegiatan pengabdian dilaksanakan setiap hari Jumat atau hari lainnya jika memang dibutuhkan. Kegiatan sosialisasi program diakhiri dengan kegiatan memastikan kesiapan serta minat peternak dalam mengikuti pelatihan pengolahan pupuk organik, dengan menyebar kuesioner pada akhir kegiatan.

Pengenalan teknologi probio_Fm di kelompok saling gumilang bertujuan untuk mengajak peternak beralih menggunakan bahan organik sebagai bahan pengurai, dalam pengolahan limbah feses sapi menjadi pupuk. Pengenalan teknologi dilakukan dengan menunjukan langsung contoh produk serta membagikan buku panduan dan brosur agar peternak mudah memahami materi (Gambar 1). Kegiatan pengenalan teknologi dilakukan sebelum pelaksanaan demontrasi pelatihan pengolahan pupuk berbasis teknologi probio_Fm. Agar penggunaan dan pengolahan pupuk berbasis teknologi probio_Fm berkelanjutan, tim pengabdi juga telah memastikan peternak trampil memproduksi probio_Fm F3.

Pengenalan teknologi probio_Fm pada kelompok Saling Gumilang memberikan hasil bahwa sebagain besar peserta yang hadir, atau sebanyak $71 \%$ peternak menyatakan setuju bahwa peternak telah memiliki pengetahuan, pernah mendengar maupun melihat produk dari teknologi probio_Fm. Peternak memeroleh informasi dan pengetahuan tentang teknologi probio_Fm dari kelompok Tunas Baru sebagai kelompok pembina, bahkan sebanyak 36\% peterak juga telah berpengalaman menggunakan teknologi probio_Fm dalam pengolahan pakan (Tabel 1).

Penerapan teknologi probio_Fm dalam pengolahan pupuk organik berasal dari feses sapi perlu dilakukan sebagai upaya optimalisasi penggunaan pupuk organik dari limbah feses sapi. Hasil wawancara berdasarkan penyebaran kuesioner pada Tabel 1 menunjukkan bahwa sebagian besar atau $50 \%$ peternak menyatakan setuju bahwa materi pelatihan pengolahan pupuk organik dengan teknologi probio_Fm diperlukan. Peternak juga menyatakan bahwa penggunaan pupuk organik dari feses sapi oleh kelompok Saling Gumilang belum optimal, hanya $21 \%$ atau sebanyak 3 orang peternak yang telah menggunakan feses sapi untuk pupuk tanaman sawit, dan peternak lainnya masih mengandalkan penggunaan pupuk kimia. Penggunaan pupuk organik dari feses sapi belum optimal juga terlihat dari cara peternak menggunkan feses sapi secara langsung tanpa adanya pengolahan. Peternak menyatakan pengolahan feses sapi menjadi pupuk kompos membutuhkan waktu dan keahlian khusus, sedangkan peternak di kelompok saling gumilang belum berpengalaman dan belum pernah memeroleh materi pelatihan pengolahan pupuk organik. Ustriyana (2011), juga menyatakan salah satu faktor penyebab peternak enggan mengolah limbah feses ternak sapi karena menilai aktivitas tersebut membutuhkan waktu dan perhatian khusus, namun demikian sebanyak 50\% peternak menyatakan berminat mengikuti pelatihan pengolahan pupuk organik dengan teknologi probio_Fm, dan berminat menggunakan maupun mengolah pupuk organik dengan teknologi probio_Fm bersama kelompok.

Tabel 1 Hasil wawancara kuesioner

\begin{tabular}{lcc}
\hline \multicolumn{1}{c}{ Indikator penilaian } & Jumlah (orang) & Persentase (\%) \\
\hline $\begin{array}{l}\text { Minat } \\
\text { - Mengikuti pelatihan pembuatan pakan silase pelepah sawit }\end{array}$ & 4 & 100 \\
- Minat memiliki mesin pencacah & 4 & 100 \\
$\begin{array}{l}\text { Penialain terhadap materi pelatihan } \\
\text { - Materi mudah dipahami peternak }\end{array}$ & 2 & 50 \\
- Materi dibutuhkan peternak & 4 & 100 \\
$\begin{array}{l}\text { Penilaian terhadap keunggulan mesin pencacah } \\
\text { - Hasil cacahan pelepah lebih halus } \\
\text { - Kapasistas mesin lebih besar }\end{array}$ & 4 \\
$\begin{array}{l}\text { Penilaian ketercapaian materi } \\
\text { - Peternak memahami alat,bahan, prosedur dalam pembuatan pakan silase } \\
\text { - Peternak trampil membuat pakans ilase pelepah sawit dengan teknologi } \\
\text { probio_Fm }\end{array}$ & 2 & 100 \\
\hline
\end{tabular}




\section{Demontrasi Pelatihan Pengolahan Pupuk Organik}

Pelaksanaan kegiatan pendampingan pengolahan pupuk organik menggunakan teknologi probio_Fm dipandu langsung oleh moderator, yaitu ketua P4S tani Tunas Baru atau kelompok pembina. Tim pengabdi melibatkan kelompok pembina untuk menularkan rasa semangat dan memberi motivasi serta kenyamanan peternak belajar. Luaran yang dihasilkan sebnyak 50\% peternak memahami materi dan terampil mengolah pupuk organik dengan teknologi probio_Fm.

Praktik pengolahan kompos dilakukan di rumah ketua kelompok tani Saling Gumilang. Pelatihan pengolahan kompos dilakukan dengan metode pendekatan partisipatif, yang bertujuan untuk memengaruhi kemandirian dan mengarahkan pada kesadaran masyarakat (Dewi 2014). Pelaksanaan kegiatan pelatihan oleh tim pengabdi diawali dengan kegiatan diskusi dan tanya jawab seputar materi pengolahan kompos. Moderator menjelaskan kepada peternak bahanbahan yang digunakan dan syarat kelayakan bahan yang baik untuk digunakan. Sebanyak 60\% peternak sepakat bahwa peternak memahami bahan dan takaran perbandingan penggunaan bahan dalam pembuatan kompos. Peternak mengetahui bahwa ciri feses yang baik untuk digunakan sebagai bahan pembuatan pupuk kompos, memiliki kadar air $<30 \%$, atau sudah berumur 10 hari. Dahono (2012) menyatakan kandungan air merupakan salah satu faktor yang memengaruhi keberhasilan dalam pembuatan pupuk kompos.

Pelaksanaan pelatihan pembuatan pupuk kompos dilanjutkan dengan praktik penimbangan bahan dan pembuatan larutan pengurai. Peternak terlibat aktif dalam praktik pe-

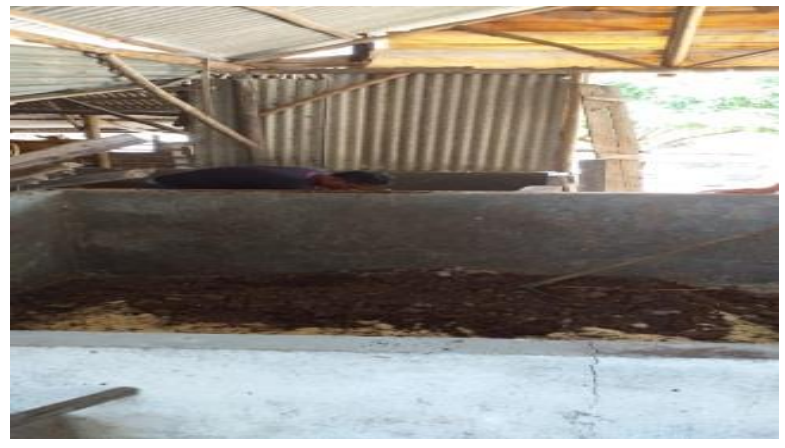

a kg. Peternak memanfaatkan serasah rumput kering dari sisa pemberian pakan di kandang. Praktik dilanjutkan dengan proses pembuatan larutan pengurai dengan cara manambahkan gula pasir $1 \mathrm{~kg}$ ke dalam larutan starter probio_Fm yang dibuat dengan perbandingan air 50 L ditambah 1 L probio_Fm.

Peternak melanjutkan kegiatan pembuatan pupuk kompos dengan melakukan proses pengadukan bahan. Bahan diaduk menggunakan sekop secara bersama-sama dilakukan oleh 4 orang peternak, pada saat yang sama bahan adukan ditaburi cairan bahan pengurai. Pengadukan bahan dilakukan sampai bahan tercampur homogen, peternak juga menambahkan air secukupnya untuk menjaga kelembaban bahan adukan. Proses pembuatan pupuk kompos diakhiri dengan proses fermentasi atau pengomposan. Sebanyak 50\% peternak memahami cara pengadukan bahan dan tebal timbunan bahan adukan. Peternak membuat hamparan dengan ketinggian atau tebal tumpukan bahan 30 $\mathrm{cm}$, ditutup menggunakan plastik. Gambar 2 menunjukkan demontrasi pelatihan pengolahan kompos.

Proses pembuatan pupuk kompos dengan teknologi Probio_FM dilanjutkan dengan kegiatan pembalikan tumpukan bahan adukan, setelah proses fermentasi berjalan 1 minggu. Kegiatan pembalikan tumpukan bahan adukan dilakukan 2 kali dan diakhiri dengan proses pemanenan. Peternak memahami bahwa proses pengadukan sangat diperlukan, tujuan pengadukan adalah untuk mengurangi suhu panas pupuk. Adriani et al. (2016) menyatakan aktivitas pengadukan kompos setelah 21 hari proses fermentasi harus dilakukan, berfungsi untuk mengurangi suhu panas pada pupuk.

Peternak membuka plastik penutup membiarkan pupuk kompos dalam kondisi terbuka

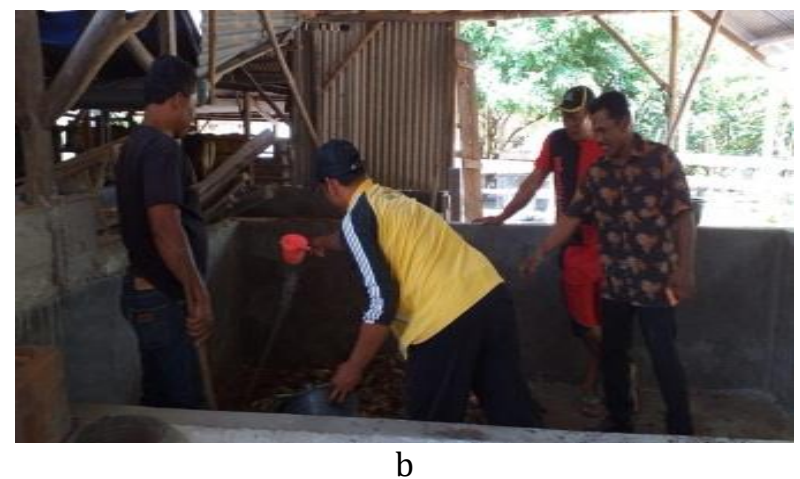

b

Gambar 2 Demontrasi pelatihan pengolahan kompos a) Persiapan bahan dan b) Pengadukan bahan.

nimbangan bahan feses ditambah serasah rumput kering sebanyak 1 ton dan dedak padi 30 atau diangin-anginkan dan pada saat yang sama dilakukan pengadukan kembali, selanjutya 
pupuk kompos siap diaplikasikan setelah 2 hari pemanenan. Peternak berhasil membuat pupuk kompos. Berdasarkan penilaian secara fisik warna pupuk kompos yang dihasilkan cokelat kehitaman, tekstur pupuk remah, dan bau tidak menyengat. Artinya pupuk kompos hasil produksi kelompok Saling Gumilang dapat dikatakan baik, karena syarat pupuk organik dikatakan baik juga berbau tidak menyengat, bewarna kehitaman, dan tekstur gembur (Syarief et al. 2016).

\section{Monitoring dan Evaluasi}

Monitoring dan evaluasi dilakukan bersamaan dengan pendampingan program. Monitoring dan evaluasi dilakukan selama dua bulan. Monitoring dan evaluasi dilaksanakan melalui kegiatan tatap muka, penyebaran kuesioner, maupun percakapann menggunakan media telekomunikasi online (whatsapp). Pelaksanaan kegiatan monitoring dan evaluasi dibantu oleh petugas pembatu lapang. Ketua P4S Tunas Baru juga berperan aktif mengawal dan mengevaluasi kegiatan peternak kelompok Saling Gumilang dalam aplikasi produk pupuk kompos. Tujuan kegiatan monitoring dan evaluasi untuk mengamati temuan di lapangan terkait kendala, hasil, dan keberlanjutan program. Hasil monitoring dan evaluasi diharapkan dapat menjadi dasar perbaikan untuk pelaksanaan program-program yang akan datang.

Hasil pendampingan program pada Tabel 1 menunjukan bahwa sebanyak 50\% peternak telah mengaplikasikan pupuk kompos untuk tanaman. Peternak Desa Lubuk Lingkuk menggunakan pupuk kompos untuk tanaman sawit, lada, maupun tanaman cabai. Hasil wawancara kuesioner pada Tabel 1 diketahui sebanyak 30\% peternak memahami cara aplikasi pupuk kompos pada berbagai tanaman. Peternak menyatakan bahwa aplikasi pupuk kompos dilakukan melalui 5 tahapan. Dosis pemakaian setiap tahapan adalah berbeda, dosis penggunaan pupuk kompos pada tahap 4 dan 5 semakin sedikit, yaitu $250 \mathrm{~kg}$ untuk luasan 1 ha tanaman. Penggunaan pupuk kompos oleh peternak bertujuan untuk upaya perbaikan kondisi kesuburan tanah, serta menjaga kesuburan tanah secara berkelanjutan.

Hasil monitoring dan evaluasi menunjukkan adanya beberapa kendala yang dihadapi peternak dalam pembuatan pupuk kompos seperti kendala pengiriman bahan starter. Bahan starter didatangkan dari Universitas Jambi. Pengiriman bahan terkendala oleh wujud bahan berbentuk cairan dan mengandung bakteri aktif, ditolak berbagai jasa ekpedisi baik darat maupun udara. Penerapan teknologi probio_Fm yang berkelanjutan baik untuk pengolahan pakan maupun pupuk organik dapat dilakukan melalui kerja sama pemerintah Bangka Tengah, Universitas Bangka Belitung, dan Universitas Jambi, dengan mendirikan laboraturium produksi bahan starter F2 di Kabupaten Bangka Tengah melalui program kemitraan wilayah.

\section{SIMPULAN}

Peternak pada kelompok Saling Gumilang berhasil dan terampil membuat pupuk kompos dari feses sapi dengan menerapkan teknologi probio_Fm. Pupuk kompos hasil produksi kelompok Saling Gumilang secara umum memiliki ciri fisik warna cokelat kehitaman, bau tidak menyengat dan memiliki tekstur gembur. Dampak adanya aktivitas pengolahan limbah feses mejadi pupuk kompos yang dirasakan peternak adalah lingkungan kandang menjadi bersih, masalah pencemaran bau disekitar kandang teratasi, serta tersedianya pupuk kompos untuk kebutuhan pupuk tanaman sawit.

\section{UCAPAN TERIMA KASIH}

Ucapan terima kasih disampaikan kepada Kemenristek Dikti yang telah memberi pendanaan untuk pelaksanaan kegiatan pengabdian masyarakat melalui hibah program kemitraan masyarakat (PKM) tahun 2019. Kepada Universitas Bangka Belitung (UBB) yang telah memberi kesempatan kepada pengabdi untuk mengikuti pendampingan penyusunan proposal pengabdian masyarakat Tahun 2019, serta kepada Universitas Jambi (UNJA) atas dukungan pengiriman bahan dan transfer teknologi yang diberikan. Kepada Dinas Pertanian Bangka Tengah atas izin dan dukungan menugaskan penyuluh lapangan mendampingi pelaksanaan program, serta kepada kelompok tani Saling Gumilang atas kesediaan dan kerja samanya menjadi mitra.

\section{DAFTAR PUSTAKA}

Adriani, Andayani J. Hamzah, Armando YG, Novianti S. 2016. Intented Change Masyarakat Pelaku Integrasi Hultikultura Dalam Penanggunalangan Bencana Asap Dilahan 
Gambut Kecamatan Kumpeh Ulu. Jurnal Karya Abdi Masyarakat. 1(2): 129-137. https:// doi.org/10.22437/jkam.v1i2.4291

Adriani, Novra A. 2017. Peningkatan Kualitas Biourin dari Ternak Sapi yang Mendapat Perlakuan Trychoderma Harzianum. Jurnal Ilmu-Ilmu Peternakan. 2: 67-78.

Astuti RP, Pranoto YS. 2018. Pemberdayaan Kelompok Tani Tunas Baru Melalui Usaha Pengolahan Biourin Berbasis Probio_Fm dalam Penerapan Sistem Integrasi Sapi Kelapa Sawit Di Bangka Tengah. Jurnal Pengabdian Kepada Masyarakat Universitas Bangka Belitung. (5)1: 36-41. https://doi.org/ 10.29244/agrokreatif.5.2.141-149

Dewi NK. 2014. Pendidikan Lingkungan Hidup bagi Masyarakat. Madiun (ID): IKIP PGRI Madiun.

Rohani S, Sirajuddin SN, Said MI, Mide MZ, Nurhapsa. 2016. Model pemanfaatan urine sapi sebagai pupuk organik cair Kecamatan Liburen Kabupaten Bone. PANRITA_ABDI Jurnal Pengabdian Kepada Masyarakat. 1(1): 11-15.

Manin F, Hendalia E, Yatno, Kompiang IP. 2003. Potensi Saluran Pencernaan Itik Lokal Kerinci sebagai Sumber Probiotik dan Implikasinya terhadap Produktivitas Ternak dan Penanggulangan kasus Salmonellosis. Laporan Penelitian Hibah Bersaing X Tahun Kedua. Jambi (ID): Universitas Jambi.

Manin F, Hendalia E, Yusrizal, Yatno. 2010. Penggunaan Simbiotik yang Berasal dari Bungkil Inti Sawit dan Bakteri Asam Laktat terhadap Performans, Lingkungan dan Status Kesehatan Ayam Broiler. Laporan Penelitian Strategi Nasional. Jambi (ID): Universitas Jambi.
Manin F. 2014. Pengembangan Industri Produk Probiotik Probio_Fm Berbasis Kemitraan. LaporanPenelitian MP3EI. Jambi (ID): LPPM Universitas Jambi.

Ustriyana ING. 2011. Analisis Nilai Tambah dan Pendapatan Usaha Pengolahan Limbah Ternak: Studi Kasus di Desa Babahan, Kecamatan Penebel, Kabupaten Tabanan. Dwijenagro. 1(2):1-5.

Okoroafor IB, Okelola EO, Edeh O, Nemehute VC, Onu CN, Nwaneri TC, Chinaka GI. 2013. Effect of Organic Manure on the Growth and Yield Performance of Maize in Ishiagu, Ebonyi State, Nigeria. IOSR Journal of Agriculture and Veterinary. 5(4): 28-31. https://doi.org/ 10.9790/2380-0542831

Dahono. 2012. Pembuatan kompos dan pupuk cair organik dari kotoran dan urin sapi. Loka pengkajian teknologi pertanian (LPTP). Kepulauan Riau (ID).

[RPJMD] Rencana Pembangunan Jangka Menengah Daerah Kabupaten Bangka Tengah Tahun 2016-2021. 2019. Pemerintah Kabupaten Bangka tengah (ID).

Syarief S, Adriani, Latief. 2016. Pengaruh penambahan beberapa starter terhadap bentu fisik dan unsur hara kompos dari kotoran kambing. Jurnal Penelitian Universitas Jambi Seri Sains. 18(2): 1-7.

Tiesnamurti B, Bahri S, Setyadi B, Priyanti A, Yusron A, Dedi SE, Handiwirawan E. 2014. Position paper tentang pedoman pengembangan sistem integrasi sawit-sapi ramah lingkungan. Jakarta (ID): Badan Penelitian dan Pengembangan Pertanian. 